\title{
Oxygen and Silicon Ion Particles Induce Neoplastic Transformation in Human Colonic Epithelial Cells
}

\author{
Sang Bum Kim, Lu Zhang ${ }^{\ddagger}$, and Jerry W. Shay \\ Department of Cell Biology, University of Texas Southwestern Medical Center, Dallas, TX \\ ${ }^{\ddagger}$ Sang Bum Kim and Lu Zhang equally share first authorship of this research.
}

\begin{abstract}
High charge (Z) and energy (E) (HZE) particles in deep space have significantly contributed to the biological effects of space radiation, although they only account for less than $1 \%$ of the galactic cosmic rays (GCR) particle fluxes. Previously we have shown that combined radiation exposure of 2-Gy proton $\left({ }^{1} \mathrm{H}\right)$ followed by 0.5 -Gy iron $\left({ }^{56} \mathrm{Fe}\right)$ ion particles increase transformation in human colonic epithelial cells (HCEC CT7). The present study was undertaken to characterize if additional HZE ions, such as oxygen $\left({ }^{16} \mathrm{O}\right)$ and silicon $\left({ }^{28} \mathrm{Si}\right)$ particles, also result in increased cell transformation. HCEC CT7 cells irradiated with 1-Gy ${ }^{16} \mathrm{O}$ (250 MeV/nucleon), followed 24 hours later by $1-\mathrm{Gy}{ }^{28} \mathrm{Si}$ particle $\quad(300$ $\mathrm{MeV} /$ nucleon), showed an increase in proliferation, anchorage-independent growth, migration, and invasion abilities compared to unirradiated controls. In addition, we found that the $\beta$-catenin pathway was activated and that subsets of DNA repair genes were underexpressed in these transformed cells.
\end{abstract}

Key words: Space Radiation, HZE Particles, Human Colonic Epithelial Cells, Transformation

Correspondence to: Jerry W. Shay

University of Texas Southwestern Medical Center

Department of Cell Biology

5323 Harry Hines Boulevard

Dallas, TX 75390-9039

Telephone: 214-633-1994

E-mail: Jerry.Shay@UTSouthwestern.edu
Pretreatment with the radioprotector, CDDO$\mathrm{Me}, 18$ hours before and during irradiation prevented the HZE-induced transformation. These results can be interpreted to suggest that the mixed radiation exposure of ${ }^{16} \mathrm{O}$ followed by ${ }^{28} \mathrm{Si}$ has carcinogenic potential. Importantly, this transformation can be protected by CDDOMe pre-treatment.

\section{INTRODUCTION}

Radiation is considered to be one of the major risk factors for humans in space and has emerged as a critical issue to be resolved for safe, long-term missions, both orbital and interplanetary. For interplanetary space, the primary components of the radiation field are galactic cosmic rays (GCR) and solar particle radiation. GCR consists of $2 \%$ electron, $85.3 \%$ protons (hydrogen nuclei), 11.8\% alpha particles (helium nuclei), and less than $1 \%$ of high charge (Z) and energy (E) (HZE) particles. Although HZE particles only account for a small amount of the GCR particle fluxes, they significantly contribute to the biological effects of space radiation (Hellweg and Baumstark-Khan, 2007). Since there is high uncertainty concerning radiation risk from heavy ions in space, as well as long-term consequences of using HZE particles in radiation oncology (Chen et al., 1981), it is important to conduct additional mechanistic studies with biological outcomes in which the scientific basis of heavy ion radiobiology remains largely unknown. Since the space radiation safety goal is to live and work safely in space with acceptable risks from radiation, a major gap in our knowledge remains 
the uncertainties in modeling increased risks of invasive (more fatal) cancers due to charged particle exposure in the space environment (Cucinotta et al., 2013). Thus, new knowledge on risks must be obtained.

Exposure to GCR results in long-term effects, such as increased risk of cancer development. Animal studies have shown that HZE particles have a higher carcinogenic effect compared to equivalent low energy radiation (e.g. gamma-rays) for tumors of the skin and mammary glands (Burns et al., 1993; Dicello et al., 2004). However, the risk of cancer development cannot be characterized fully and modeled until the relation between the radiation type and cancer incidence is defined adequately. To address the carcinogenic effects of HZE particles in vitro, we established non-cancerous immortalized human colonic epithelial cells (HCEC CT7) which harbor one of the initial alterations (trisomy chromosome 7) that occur in up to $\sim 40 \%$ of colonic benign polyp (adenomas) (Habermann et al., 2007; Ly et al., 2011). These cells are a useful in vitro human cell model to study the malignant progression of premalignant cells after radiation exposure.

Previously we demonstrated that combined exposure with proton and iron ions radiation, but not single ion exposures, to HCEC CT7 cells increased both the proliferation rate and anchorage-independent growth in vitro (Eskiocak et al., 2010). We also demonstrated that the synthetic triterpenoid 2-cyano-3,12dioxooleana-1,9 (11)-dien-28-oic acid (CDDO) along with chemically modified derivatives CDDO-methyl ester, which are noncytotoxic and highly multifunctional drugs, had radioprotection activity in vivo and in vitro (Eskiocak et al., 2010; Kim et al., 2012). What was not known from these studies is if other HZE ion combinations would also increase cell transformation and if so, if the CDDO-methyl ester would be an effective radioprotector. Relative biological effectiveness (RBE) of accelerated HZE particles has been calculated by a variety of methods, including measuring chromosomal aberrations in human lymphocytes (George et al., 2003; George et al., 2013). Estimated RBE values for $0.5-\mathrm{Gy}{ }^{56} \mathrm{Fe}$ and 1 Gy ${ }^{28} \mathrm{Si}$ are 17.8 and 9.9, respectively. RBE for $1-\mathrm{Gy}{ }^{16} \mathrm{O}$ is much lower compared to ${ }^{28} \mathrm{Si}$. Since we previously reported that $0.5-\mathrm{Gy}{ }^{56} \mathrm{Fe}$ irradiation alone did not provide a significant growth advantage using partially transformed HCEC CT7 cells (Eskiocak et al., 2010), we decided to use lower RBE doses of ${ }^{28} \mathrm{Si}$ and ${ }^{16} \mathrm{O}$ for this study. In the current study, we describe the carcinogenic potential of combined HZE particles exposure of 1-Gy of 250 $\mathrm{MeV} /$ nucleon ${ }^{16} \mathrm{O}$ ions, followed by 1-Gy of 300 $\mathrm{MeV} /$ nucleon ${ }^{28} \mathrm{Si}$ ions using HCEC CT7, and also evaluated the radioprotection effect of CDDO-Me against these HZE particles.

\section{MATERIALS AND METHODS}

\section{Cell Culture and Irradiation}

Telomerase immortalized, but noncancerous HCEC CT7s were established and maintained under low oxygen $(2 \%$ oxygen and $5 \%$ carbon dioxide) on Primaria ${ }^{\circledR}$ plates (BD Bioscience, San Jose, CA) as described previously (Ly et al., 2011; Roig et al., 2010). For HZE irradiation, $4 \times 10^{4}$ cells were seeded into T25 flask six days prior to irradiation. Cells were shipped to the NASA Space Radiation Laboratory (NSRL) (Upton, NY) and maintained in a low oxygen incubator. HZE particle irradiations were performed at the NSRL with a mixed-field radiation scheme in which cells were exposed to 1-Gy of 250 $\mathrm{MeV} /$ nucleon ${ }^{16} \mathrm{O}$ particles and then exposed to $1-\mathrm{Gy}$ of $300 \mathrm{MeV} /$ nucleon ${ }^{28} \mathrm{Si}$ particles on the following day.

To address radioprotection activity of CDDO-Me, the cells were treated with $50 \mathrm{nM}$ CDDO-Me (Kim et al., 2012) 18 hours before first irradiation. The medium was changed after first irradiation with medium containing $50 \mathrm{nM}$ CDDO-Me. After the last irradiation, cells were changed with fresh medium and shipped back to University of Texas (UT) Southwestern. An equivalent amount of DMSO was used as a vehicle control.

At UT Southwestern, half of the cells were frozen and stored for further assays and the other half of cells were passage cultured for four weeks in the absence of CDDO-Me. Unirradiated control cells were also sent along with other cells to the NSRL, maintained in the same facility, and shipped back to UT Southwestern; they were placed on the radiation 
platform but were not irradiated. The first proliferation and soft agar assays were performed four weeks after irradiation. Several months later, the second proliferation and soft agar assays were validated using frozen/stored cells four weeks after passage culture. Other assays were also performed using frozen/stored cells four weeks after passage culture (Supplementary Figure S1).

\section{Proliferation Rate Assay}

Cells were seeded at a density of $10^{4}$ cells/well in triplicate (technical replicate) 6well plates and incubated. Cells were detached using $\quad 0.05 \%$ Gibco ${ }^{\circledR}$ Trypsin-EDTA (Life Technology, Grand Island, NY) and suspended cells were counted at two day intervals over a seven day period using a Z1 Coulter Counter ${ }^{\circledR}$ (Beckman, Indianapolis, IN). Each experiment was repeated using cells from different cell suspensions (biological replicate).

\section{Scratch Wound Healing Assay}

1CT7 cells were seeded at a density of $5 \mathrm{x}$ $10^{5}$ cells/well in triplicate 6-well plates. A single wound was created in the center of the confluent cell monolayer by removal of the attached cells with a sterile plastic pipette tip. The debris was removed by washing with phosphate buffered saline (PBS) and cells photographed using an EVOS ${ }^{\circledR}$ microscope (Westover Scientific, Life Technology) to measure the distance of the wounded area. After 24 hours of incubation with growth medium containing $1 \mathrm{mM}$ thymidine (proliferation inhibitor, Sigma), the same areas were photographed to measure a ratio of wound closure. The wound closure was quantified by measuring the length between the wound borders by Image J software (NIH, Bethesda, $\mathrm{MD})$ per $4 \mathrm{x}$ fields of view measuring three fields per plate. The ratio of wound closure was calculated by [(length of closed are) / (length of wounded area $\times 100(\%)$. Each experiment was repeated independently using cells from different cell suspensions.

\section{Soft Agar Assay}

Cells were suspended in $0.375 \%$ Noble agar (Difco, Detroit, MI) in supplemented basal medium at a density of 1,000 cells and overlaid on $0.75 \%$ Noble agar in 24 -well plates. Each sample was seeded in triplicate and incubated at $37^{\circ} \mathrm{C}$ for four weeks. Colonies larger than 0.1 $\mathrm{mm}$ were counted. The experiment was repeated independently using cells from different cell suspensions. Colonies were photographed using a stereo microscope (SteREO Discovery, Carl Zeiss, Thornwood, NY) and colony size was determined using a measuring tool in Image J software.

\section{Invasion Assays}

$10^{5}$ cells were serum-starved overnight, suspended in $300-\mu 1$ of basal medium, and plated onto $8.0-\mu \mathrm{m}$ pore $\mathrm{BD}$ Matrigel $^{\mathrm{TM}}$ Invasion Chamber (\#354480, BD Biosciences, Bedford, MA). $500-\mu 1$ of medium containing $2 \%$ serum and growth supplements was added to the bottom well. After incubation for 24 hours, cells were fixed and stained using a mixture of $6.0 \%$ (vol/vol) glutaraldehyde and $0.5 \%$ crystal violet for $10 \mathrm{~min}$. Non-migratory cells on the upper surface on the filter were scraped off and migratory cells on the lower compartment were photographed by Axioskop 2 (Carl Zeiss, Thornwood, NY) and counted using ImageJ. Experiments were performed twice using different cell suspension for biological replicates in triplicate invasion chambers. Invading cells were quantified by averaging the number of stained cells per $4 \mathrm{x}$ field of view counting five fields per chamber.

\section{Western Blot}

Passage cultured cells four weeks after irradiation were harvested and total cell lysates were prepared in Laemmli SDS reducing buffer (50 mM Tris- $\mathrm{HCl}$ (pH 6.8), 2\% SDS, and 10\% glycerol), boiled, and resolved on an $4-15 \%$ Mini-PROTEAN TGX ${ }^{\mathrm{TM}}$ Precast Gel, and transferred to a polyvinylidinefluoride membrane using the Trans-Blot ${ }^{\circledR} \quad$ Turbo $^{\text {TM }}$ Transfer System (Bio-Rad, Hercules, CA). The following antibodies were used: anti-Active- $\beta$ catenin (1:1000, Millipore, 05-665), anti-cyclin D1 (1:1000, Cell Signaling, 2978S), and antiphospho-Stat3 (Tyr705, 1:1000, Cell Signaling, 9145S). HRP-conjugated goat, anti-mouse, or anti-rabbit (Jackson ImmunoResearch) were used as secondary antibodies at 1:5000 and detected with the SuperSignalWest Pico Chemiluminescent Substrate Kit (Thermo 
Scientific) and the gel documentation system, G:BOX (Syngene, Frederick, MD). Experiments were performed twice using different cell suspension.

\section{DNA Repair PCR Array}

Total RNA was isolated from cells passagecultured for four weeks after irradiation using RNeasy Plus Mini kit (Qiagen, Chatsworth, $\mathrm{CA}$ ), according to the manufacturer's protocol. Then $1 \mu \mathrm{g}$ total RNA was converted to cDNA in $20 \mu \mathrm{l}$ reaction using $\mathrm{RT}^{2}$ First Strand Kit (Qiagen, Chatsworth, CA) and $91 \mu 1$ RNase-free water was added to dilute. The Human DNA Repair $\mathrm{RT}^{2}$ Profiler $^{\mathrm{TM}}$ PCR Array (Qiagen, Chatsworth, CA) was used for screening, per the manufacturer's protocol. Real-time quantitative PCR reactions were set up with $\mathrm{RT}^{2}$ qPCR Master Mixes (Qiagen, Chatsworth, CA) and run on the LightCycler 480 II (Roche) with 45 cycles of denaturation $\left(95^{\circ} \mathrm{C}, 15 \mathrm{sec}\right)$ and annealing $\left(60^{\circ} \mathrm{C}, 1 \mathrm{~min}\right)$ cycle. Experiments were performed twice using different cell suspension.

\section{RESULTS}

\section{Space Radiation Confers Growth Advantage and Induces Neoplastic Transformation}

We previously reported that combined radiation exposure to $2-\mathrm{Gy}{ }_{56} \mathrm{H}$ followed by 0.5 Gy ${ }^{56} \mathrm{Fe}$ ion particles increased proliferation and anchorage-independent growth in HCEC CT7 cells (Eskiocak et al., 2010). In this study, we set out to investigate whether radiation exposure to other ions, such as ${ }^{16} \mathrm{O}$ and ${ }^{28} \mathrm{Si}$ particles, had similar effects on HCEC CT7 cells. This is important since in space, astronauts will be exposed to mixed fields of varying ion types, and while there is mounting data on single ion exposures, mixed-field experiments are mostly lacking. We employed a mixed-field radiation scheme in which cells were exposed to $1-\mathrm{Gy}{ }^{16} \mathrm{O}$ radiation at an energy of $250 \mathrm{MeV} /$ nucleon, followed 24 hours later by $1-\mathrm{Gy}{ }^{28} \mathrm{Si}$ radiation at an energy of $300 \mathrm{MeV} /$ nucleon. Irradiated cells were split; half of the cells were frozen and stored for further assays and the other half of cells were passage cultured for four weeks and then subjected to a series of functional cell transformation assays.
The first proliferation and soft agar assays, which were done four weeks after irradiation, show the irradiated cells exhibit a proliferative and anchorage-independent growth advantage compared to unirradiated control cells (Figure S2). The proliferation and soft agar data were validated using frozen/stored cells four weeks after passage culture. The irradiated and differently passage-cultured cells also exhibit a proliferative advantage in a short-term growth assay compared to unirradiated cells. These cells also show enhanced anchorage-independent growth, which is a characteristic of malignant cells. The number of colonies (1.8-fold, $\mathrm{p}<0.001$ ), as well as the sizes of the colonies (1.4-fold, $\mathrm{p}<0.001$ ), were significantly increased in the irradiated cells (Figure 2A and Figure B). Additionally, irradiation promotes increased migratory capability $(2.3$-fold, $\mathrm{p}<0.0001)$ of these cells, as is demonstrated by the scratch migration assay (Figure 2C). Finally, the invasion ability $(3.0$-fold, $\mathrm{p}<0.001)$ through extracellular matrices (Figure 2D) was significantly increased, another indicator of the cells' metastatic ability.

\section{Space Radiation Alters $\beta$-Catenin Signaling and Affects DNA Repair Genes Expression}

Signal transducer and activator of transcription 3 (Stat3) mediates the expression of a variety of genes in response to cell stimuli, and thus plays a key role in many cellular processes, such as cell growth and the regulation of apoptosis. Recently, it has been reported that loss of Stat 3 activity enhances cell proliferation and induces cancer progression by regulating expression of important regulators of colon cancer, such as $\beta$-catenin and cyclin D1 (Musteanu et al., 2010). Abnormally activated $\beta$ catenin and cyclin D1pathway are well-known biomarkers for most colorectal cancers and for a proportion of other neoplasias (Clevers and Nusse, 2012). In the current study we observed decreased level of Tyr-705-phosphorylated Stat3, resulting in increased level of active- $\beta$ catenin and cyclin D1 in the transformed cells (Figure 3A), indicating increased tumorigenesis.

Defects in expression of DNA repair genes result in chromosome instability and may be an additional high risk factor for progression from benign to malignant colorectal cancer (Jin et al., 
2005). Using a qPCR-based DNA repair gene array, we found that several DNA repair genes (XRCC3, MSH5, PARP2, TOP3B, and MMS19) were significantly $(p<0.05)$ underexpressed in the irradiation transformed cells, but remained at control levels in CDDO-Memediated protected cells (Figure 3B).

\section{CDDO-Me Protects Cells Against Space Radiation-Induced Transformation}

Since CDDO-Me has been shown to protect cells and animals against irradiation (Eskiocak et al., 2010; Kim et al., 2012), we next examined if it has the same protective effects for cells exposed to ${ }^{16} \mathrm{O}$ and ${ }^{28} \mathrm{Si}$ particles. Compared to unprotected irradiated cells, treatment with CDDO-Me before or during irradiation reduced the cell proliferation (Figure 1). CDDO-Me also reduced anchorage-independent growth, cell migration, and invasion ability compared to the irradiated cells without the radioprotector (Figure 4A-D). CDDO-Me treatment alone has undetectable effects in unirradiated cells. These data document that nontoxic pretreatment with CDDO-Me can potentially prevent HZE particle-induced cell transformation.

\section{DISCUSSION}

In a previous study, we evaluated the effect of ${ }^{1} \mathrm{H}$ and ${ }^{56} \mathrm{Fe}$ particles on increased proliferation and anchorage-independent growth of HCEC CT7 human colonic epithelial cells (Eskiocak et al., 2010). Since $0.5-\mathrm{Gy}{ }^{56} \mathrm{Fe}$ (1 $\mathrm{GeV} /$ nucleon) alone did not provide a significant growth advantage in HCEC CT7 cells, but combinations of ${ }^{56} \mathrm{Fe}$ and ${ }^{1} \mathrm{H}$ did (Eskiocak et al., 2010), this suggests single ion irradiation events, even in partially progressed cells, may be insufficient for malignant transformation. The present study extended the previous investigation using different types of HZE particles, i.e., $250 \mathrm{MeV} /$ nucleon ${ }^{16} \mathrm{O}$ ions and $300 \mathrm{MeV} /$ nucleon ${ }^{28} \mathrm{Si}$ ions, to produce carcinogenic effects and induce transformation in HCEC CT7 cells in vitro. Non-cancerous HCEC CT7 cells, four weeks after exposure to combined oxygen and silicon particles, showed increased proliferation rate (Figure 1), anchorage-independent growth, migration, and invasion ability (Figure 2) compared to unirradiated controls, whereas administration of CDDO-Me abolished the radiation-induced transformation in the cells irradiated with both oxygen and silicon (Figure 4). This is important since a nontoxic treatment with CDDO-Me could prevent cancer progression in preneoplastic cells, even when exposed to two HZE particle irradiations.

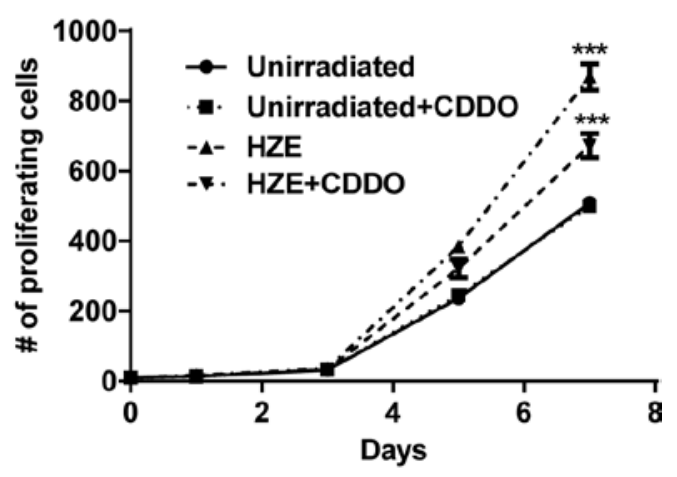

Figure 1. HZE particles increase growth advantage. HCEC CT7 cells were seeded in 6-well plate in triplicate and counted at 2 day intervals over a 7 day period. Irradiation promotes cellular proliferation rate, whereas CDDO-Me pretreatment attenuates this effect. Data represent mean \pm s.d. of repeated experiments. ${ }^{* * *} p<0.005$ in Student's t-test.

Other groups are investigating the carcinogenic effects of HZE particles in vivo. Exposure to iron ions (Dicello et al., 2004) or carbon ions (Imaoka et al., 2007) increased the risk of mammary tumors development. In addition, skin tumors increased after exposure to neon or argon ions (Burns et al., 1993; Burns et al., 2007). Although, the risk of HZE particles in cancer development is now widely studied in vivo, currently there is insufficient data to conclude that HZE particles have unique carcinogenic properties, or that mixed fields of irradiation with a variety of ions produce the same effects as single ion exposures. This gap highlights the need for a better understanding of the mechanisms underlying carcinogenic effects with different types of HZE particles in vitro, preferably using human cells. Many studies reported acute effects of HZE particles on DNA damage or oxidative stress, but there are limited mechanistic studies for HZE particles-induced tumorigenesis in vitro. 
A.

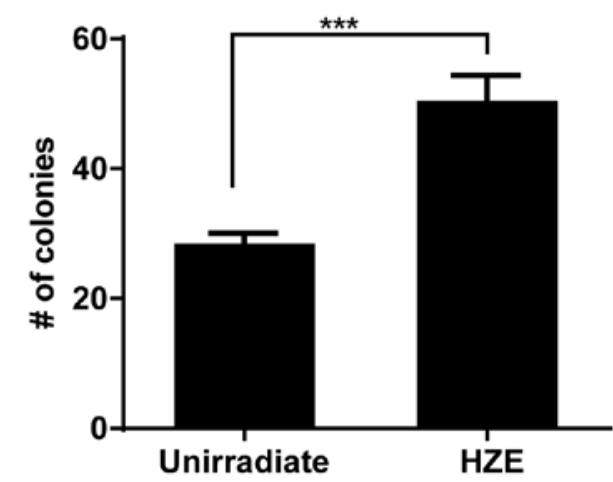

C.

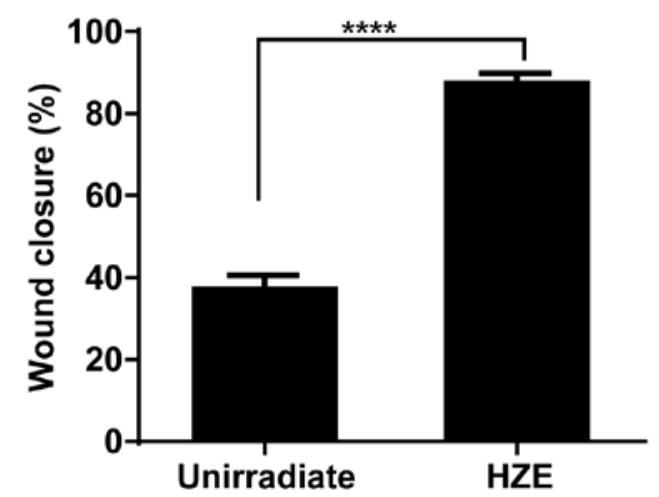

B.

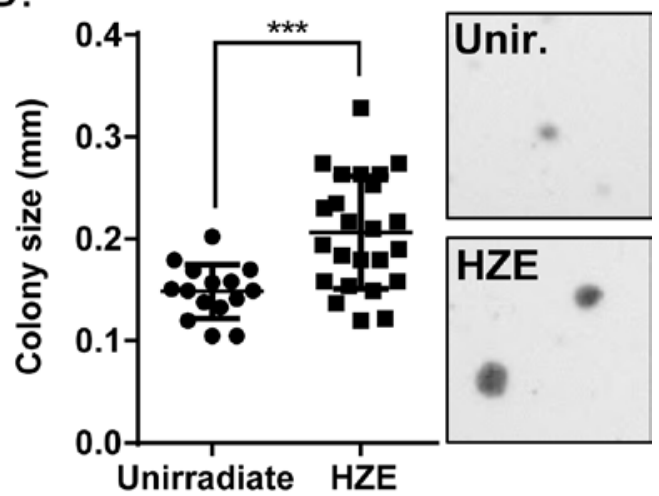

D.

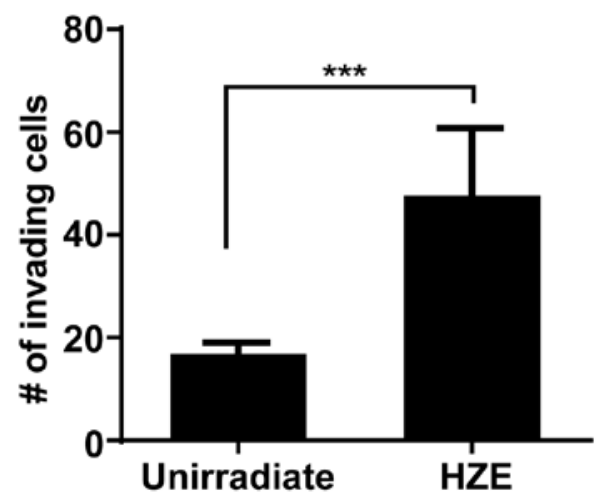

Figure 2. HZE particles increase neoplastic transformation. (A) HZE particles increase number of colonies formed in soft agar. (B) Sizes of soft agar colonies are bigger in HZE particle-irradiated cells than in unirradiated controls, as shown in the representative photographs and quantification. Colony size was measured from 15 to 25 colonies in each group. (C) HZE particles enhance cell migration in wound healing assay. (D) HZE particles promote invasion through Matrigel ${ }^{\circledR}$. Data represent mean \pm s.d. of repeated experiments. $* * * \mathbf{p}<0.005, * * * * \mathbf{p}<0.001$ in Student's $t$-test.

Our studies described a decrease in phosphorylation of Stat3 (Y705) long-term (four weeks), after exposure to oxygen and silicon particles (Figure 3A). Stat3 has dual functions in cancer development. An increased level of phospho-Stat3 (Y705) has been associated with lymph node metastasis of various tumor types and considerably up-regulated in colorectal cancer (Horiguchi et al., 2002; Kusaba et al., 2005). However, a recent study shows Stat3's tumor suppressor functions (Musteanu et al., 2010). This study indicated that intestinal epithelial cell-specific loss of Stat3 enhanced progression of benign adenomas to invasive carcinomas in Villin-cre:Stat $3^{\text {flox/flox }} \mathrm{Apc}^{\mathrm{Min} /+}$ mice (Musteanu et al., 2010). Microarray and histology data from Stat3-deficient intestinal tumors showed an increase in nuclear $\beta$-catenin and cyclin D1 (Musteanu et al., 2010).

Consistently, active- $\beta$-catenin and cyclin D1 protein levels, as assessed by Western blot analyses, were increased in our transformed cells (Figure 3A), which might contribute to the enhanced proliferation. It also has been reported that loss of Stat3 enhances intestinal tumor progression and invasiveness (Musteanu et al., 2010), which might explain an increased anchorage-independent growth and invasive ability in these transformed cells studies (Figure 2A and Figure 2D). We also observed downregulation of DNA repair genes expression in transformed cells (Figure 3B), which might result in chromosome instability and may be a high risk factor for colorectal cancer progression (Jin et al., 2005). 
A.

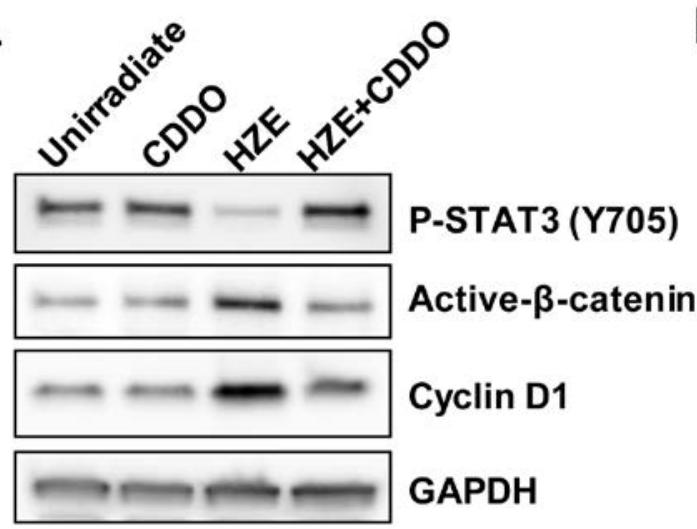

B.

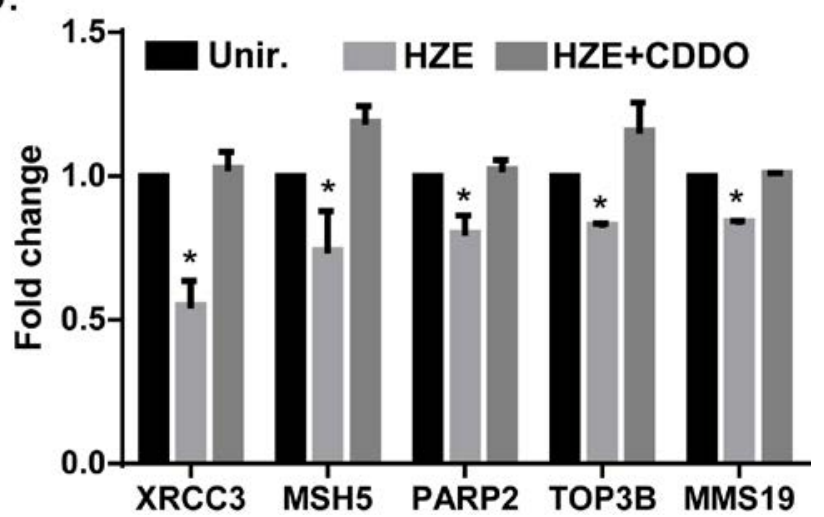

Figure 3. HZE particles activate $\beta$-catenin signaling and affect DNA repair genes expression. (A) HZE particles decrease level of phospho-Stat3 (Y705), whereas increase level of active- $\beta$-catenin and cyclin D1 expression. CDDO-Me treatment reverses these effects. GAPDH is used as loading control. (B) HZE particles decrease series of DNA repair genes expression using DNA repair gene array. ${ }^{*} p<0.05$ in Student's $t$-test in repeated experiments.

A.

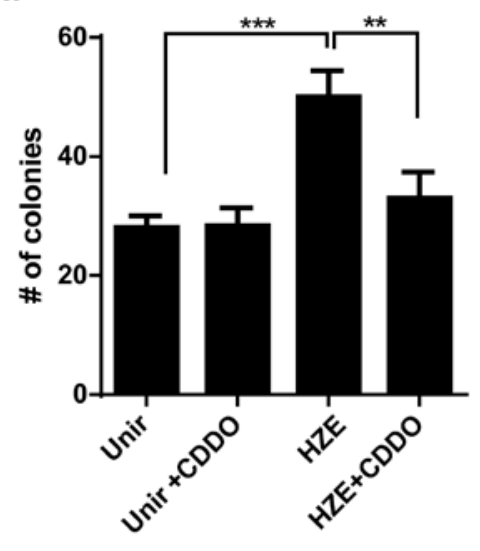

C.

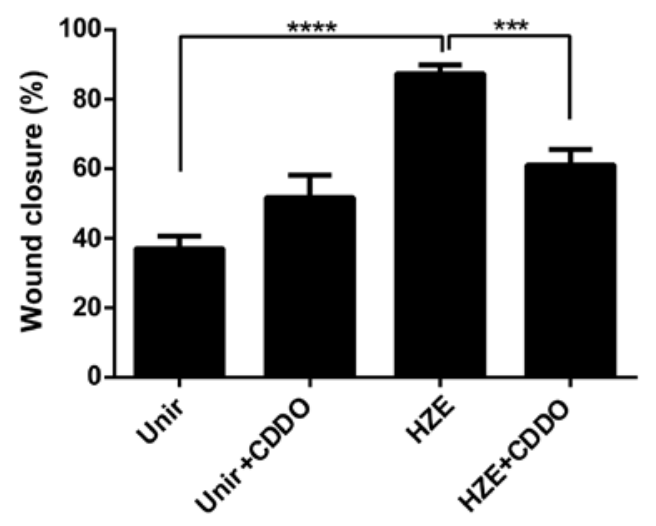

B.

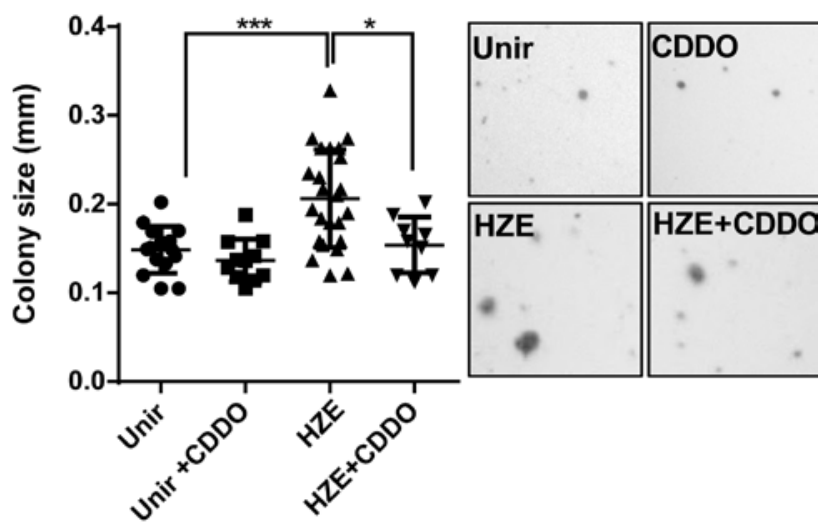

D.

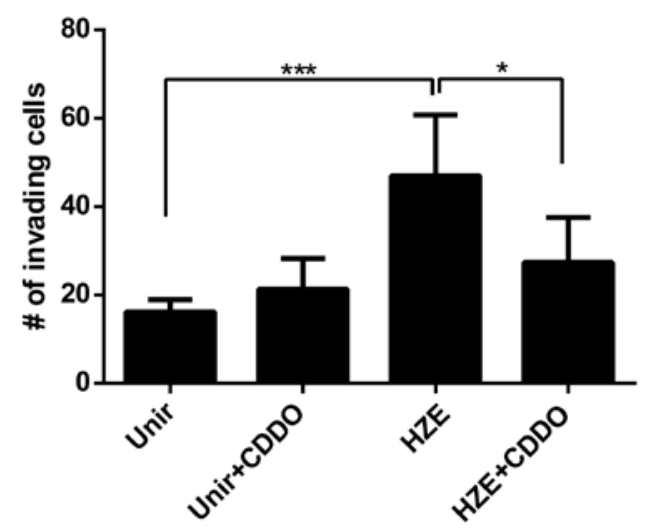

Figure 4. CDDO-Me protects cells against HZE particles. Treatment of CDDO-Me before and during irradiation reverses transformative properties of irradiated HCEC CT7 cells in terms of number of soft agar colonies (A), sizes of soft agar colonies (B), cell migration (C), and invasion through Matrigel ${ }^{\circledR}$ (D). CDDO-Me treatment alone does not have any significant effects. Data represent mean \pm s.d. of repeated experiments. ${ }^{*} \mathbf{p}<0.05, * * \mathbf{p}<0.01, * * * \mathbf{p}<0.005, * * * * \mathbf{p}<0.001$ in Student's $t$-test. 
Previously, we have shown that treatment of the anti-inflammatory, anti-oxidative compound CDDO-Me, prior to or post irradiation, modulates radiosensitivity in vitro and in vivo (Kim et al., 2013; Kim et al., 2012) and also protects cells against proton and iron particlesinduced transformation in vitro (Eskiocak et al., 2010). The current study also consistently demonstrates radioprotection effects of CDDOMe against oxygen and silicon particles mixedfield irradiations. Taken together, these studies indicate the importance of preventing space radiation-induced transformation, and suggest that CDDO-Me may be a useful biological radio-protector in reducing the uncertainties in cancer development from exposure to HZE particles of future NASA crews on long-term interplanetary space missions.

\section{ACKNOWLEDGEMENTS}

We thank the support team at Brookhaven National Laboratory (BNL) and NASA Space Radiation Laboratory (NSRL) (Upton, NY) for helping with the HZE particles delivery to cells. This work was performed in laboratories constructed with support from NIH grant C06 RR30414. This work was supported by NASA Grants NNX11AC15G and NNX09AU95G to JWS.

\section{REFERENCES}

Burns FJ, Jin Y, Koenig KL, Hosselet S (1993) The low carcinogenicity of electron radiation relative to argon ions in rat skin. Radiation Research 135: 178-188

Burns FJ, Tang MS, Frenkel K, Nadas A, Wu F, Uddin A, Zhang R (2007) Induction and prevention of carcinogenesis in rat skin exposed to space radiation. Radiation Environmental Biophysics 46: 195-199

Chen GT, Castro JR, Quivey JM (1981) Heavy charged particle radiotherapy. Annual Review of Biophysics and Bioengineering 10: $499-529$

Clevers H, Nusse R (2012) Wnt/beta-catenin signaling and disease. Cell 149: 1192-1205

Cucinotta FA, Kim MH, Chappell LJ, Huff JL (2013) How safe is safe enough? Radiation risk for a human mission to Mars. PLoS One 8: e74988

Dicello JF, Christian A, Cucinotta FA, Gridley DS, Kathirithamby R, Mann J, Markham AR, Moyers MF, Novak GR, Piantadosi S, Ricart-Arbona R, Simonson DM, Strandberg JD, Vazquez M, Williams JR, Zhang Y, Zhou H, Huso D (2004) In vivo mammary tumourigenesis in the Sprague-Dawley rat and microdosimetric correlates. Physics in Medicine and Biology 49: 3817-3830

Eskiocak U, Kim SB, Roig AI, Kitten E, Batten K, Cornelius C, Zou YS, Wright WE, Shay JW (2010) CDDO-Me protects against space radiation-induced transformation of human colon epithelial cells. Radiation Research 174: $27-36$

George K, Durante M, Willingham V, Wu H, Yang TC, Cucinotta FA (2003) Biological effectiveness of accelerated particles for the induction of chromosome damage measured in metaphase and interphase human lymphocytes. Radiation Research 160: 425435

George KA, Hada M, Chappell L, Cucinotta FA (2013) Biological effectiveness of accelerated particles for the induction of chromosome damage: track structure effects. Radiation Research 180: 25-33

Habermann JK, Paulsen U, Roblick UJ, Upender MB, McShane LM, Korn EL, Wangsa D, Kruger S, Duchrow M, Bruch HP, Auer G, Ried T (2007) Stage-specific alterations of the genome, transcriptome, and proteome during colorectal carcinogenesis. Genes Chromosomes and Cancer 46: 10-26

Hellweg CE and Baumstark-Khan C (2007) Getting ready for the manned mission to Mars: the astronauts' risk from space radiation. Naturwissenschaften 94: 517-526

Horiguchi A, Oya M, Shimada T, Uchida A, Marumo K, Murai M (2002) Activation of signal transducer and activator of transcription 3 in renal cell carcinoma: a study of incidence and its association with pathological features and clinical outcome. Journal of Urology 168: 762-765

Imaoka T, Nishimura M, Kakinuma S, Hatano Y, Ohmachi Y, Yoshinaga S, Kawano A, Maekawa A, Shimada Y (2007) High 
relative biologic effectiveness of carbon ion radiation on induction of rat mammary carcinoma and its lack of $\mathrm{H}$-ras and Tp53 mutations. International Journal of Radiation Oncology Biology Physics 69: 194-203

Jin MJ, Chen K, Song L, Fan CH, Chen Q, Zhu YM, Ma XY, Yao KY (2005) The association of the DNA repair gene XRCC3 Thr241Met polymorphism with susceptibility to colorectal cancer in a Chinese population. Cancer Genetics and Cytogenetics 163: 38-43

Kim SB, Ly P, Kaisani A, Zhang L, Wright WE, Shay JW (2013) Mitigation of radiationinduced damage by targeting EGFR in noncancerous human epithelial cells. Radiation Research 180: 259-267

Kim SB, Pandita RK, Eskiocak U, Ly P, Kaisani A, Kumar R, Cornelius C, Wright WE, Pandita TK, Shay JW (2012) Targeting of Nrf2 induces DNA damage signaling and protects colonic epithelial cells from ionizing radiation. Proceedings of the National Academy of Sciences USA 109: E2949-2955
Kusaba T, Nakayama T, Yamazumi K, Yakata Y, Yoshizaki A, Nagayasu T, Sekine I (2005) Expression of p-STAT3 in human colorectal adenocarcinoma and adenoma; correlation with clinicopathological factors. Journal of Clinical Pathology 58: 833-838

Ly P, Eskiocak U, Kim SB, Roig AI, Hight SK, Lulla DR, Zou YS, Batten K, Wright WE, Shay JW (2011) Characterization of aneuploid populations with trisomy 7 and 20 derived from diploid human colonic epithelial cells. Neoplasia 13: 348-357

Musteanu M, Blaas L, Mair M, Schlederer M, Bilban M, Tauber S, Esterbauer H, Mueller M, Casanova E, Kenner L, Poli V, Eferl R (2010) Stat3 is a negative regulator of intestinal tumor progression in Apc(Min) mice. Gastroenterology 138: 1003-1011, e1001-1005

Roig AI, Eskiocak U, Hight SK, Kim SB, Delgado O, Souza RF, Spechler SJ, Wright WE, Shay JW (2010) Immortalized epithelial cells derived from human colon biopsies express stem cell markers and differentiate in vitro. Gastroenterology 138: 1012-1021, e1011-1015 


\section{Supplemental Figures}

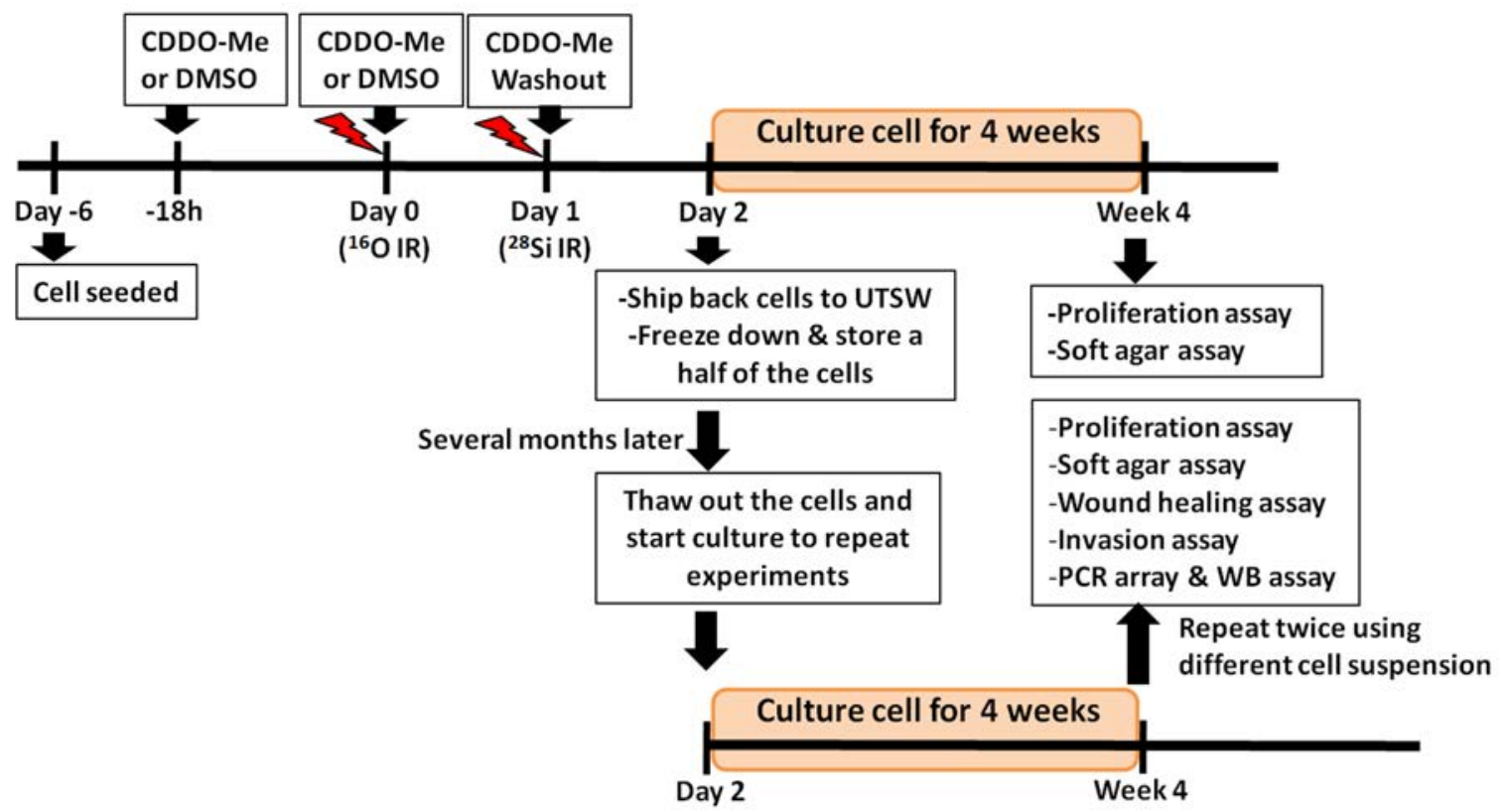

Supplementary Figure S1. Schematic flow-chart of experimental timeline. $4 \times 10^{4}$ cells were seeded into T25 flask 6 days prior to irradiation. Cells were shipped to the NASA Space Radiation Laboratory (NSRL) (Upton, NY) and maintained in a low oxygen incubator. HZE particle irradiations were performed at the NSRL with a mixed-field radiation scheme in which cells were exposed to $1-G y$ of $250 \mathrm{MeV} / \mathrm{nucleon} 160$ particles and then exposed to 1-Gy of $300 \mathrm{MeV} /$ nucleon 28Si particles on the following day. To address radioprotection activity of CDDO-Me, the cells were treated with $50 \mathrm{nM}$ CDDO-Me $18 \mathrm{~h}$ before first irradiation. The medium was changed after first irradiation with medium containing $50 \mathrm{nM}$ CDDO-Me. After the last irradiation, cells were changed with fresh medium and shipped back to UT Southwestern. Irradiated cells were split, a half of the cells were frozen and stored for further assays, and the other half of cells were passage cultured for 4 weeks and then subjected to proliferation and soft-agar assays.
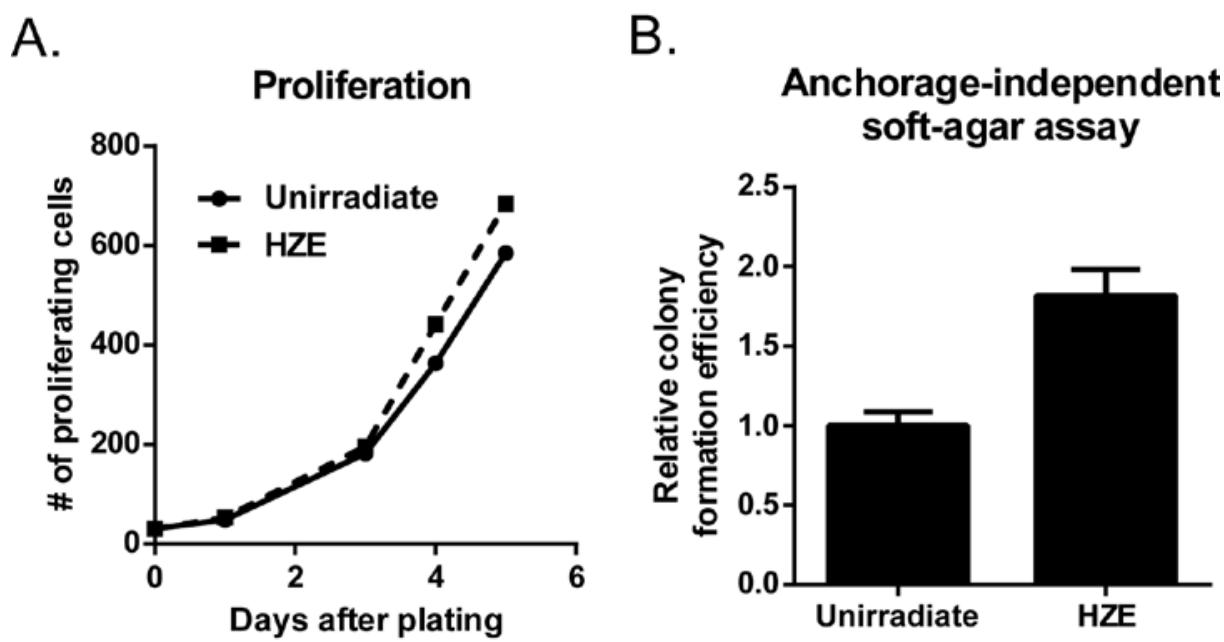

Supplementary Figure S2. The first proliferation and soft-agar assays were performed 4 weeks after irradiation. A. HCEC CT7 cells which were passage-cultured for 4 weeks after irradiation were seeded in triplicate 6-well plates and counted at 2 day interval over a 7 day period. B. Cells which were passagecultured for 4 weeks after irradiation were seeded in $0.375 \%$ soft-agar in triplicate 24 -well plates. 4 weeks later, colonies larger than $0.1-\mathrm{mm}$ diameter were counted and normalized to unirradiated control. 